\title{
Value-addition of silk using natural dye extracted from Lichen (Evernia cirrhatum)
}

\begin{abstract}
Harsha Rawat*
Department of Clothing and Textiles, G. B. Pant University of Agriculture and Technology, Pantnagar-263145 (Uttarakhand), India

Ekta Sharma

Department of Textiles and Apparel Designing, Ethelind School of Home Science, Sam Higginbottom University of Agriculture Technology \& Sciences, Allahabad - 211007 (UP), India

Nargis Fatima

Department of Textiles and Apparel Designing, Ethelind School of Home Science, Sam Higginbottom University of Agriculture Technology \& Sciences, Allahabad - 211007 (UP), India

*Corresponding author. E-mail: harsharawat.rawat@gmail.com

Abstract

The natural dyes are used since pre-historic times for colouring the wide varieties of fibres for providing value addition, look and desire of the customer. In this study among the different sources of Lichen, Evernia cirrhatum was used to standardise the dyeing recipe for degummed silk cloth. A series of experiments were conducted to optimize the dyeing variables viz., medium of dye extraction, concentration of dye material, dye extraction time and dyeing time. The dyed fabric was then treated with chemical auxiliaries and fastness test was undertaken. Aqueous medium was used by taking $2 \mathrm{~g}$ of $E$. cirrhatum dye per $100 \mathrm{ml}$ of water with 60 minute extraction time and 60 minute dyeing time was found to be optimum. In case of chemical auxiliaries, $2 \%$ of citric acid, $2 \%$ of sodium sulphate, $3 \%$ of oxalic acid and $4 \%$ tartaric acid with simultaneous dyeing method was found as best. It was observed that the dyed silk exhibited good to excellent colour fastness to washing and perspiration, no stain on rubbing and very good for light fastness. The chemical auxiliaries that exhibit best fastness characteristic were sodium sulphate and tartaric acid with fastness grade of good to excellent for washing and perspiration fastness slight stain to no stain for rubbing fastness and good to very good for light fastness.
\end{abstract}

Keyword: Chemical auxiliaries, Colourfastness properties, Lichen, Natural dyes

\section{INTRODUCTION}

Textiles had played a very important role in the development of any country since ancient times. The Indian textile sector is the second largest manufacturer and exporter of textile products in the world. The production of textile industries contribute towards $10 \%$ of the total production, $13 \%$ export earnings and about $2 \%$ Gross Domestic Production of India. Around 45 million people are employed directly and 60 million people are engaged in allied sector (Ministry of Textiles, Government of India, 2017). At present in India there are about 50 units of dye industry in organised sector and 900 units in the small scale sector, with a total aggregate installed capacity of $1,50,000$ tonnes per annum (Maharashtra industrial and economic development association, 2018). Due to inefficiency of dyeing process every year up to 200,000 tonnes of dyes were lost as effluent during the dyeing and finishing operations in the textile industries (Ogugbue and Sawidis, 2011). The dye effluent were also resist to conventional waste water treatment and due to complex aromatic structure also recalcitrant to biodegradation (Przystaś, 2012). Many synthetic dyes are also responsible for causing cancer and other health hazards. Consumers nowadays are becoming more concerned about environmental issues and hence are demanding for natural product incorporating natural ingredients. Presently the share of natural dyes is only $1 \%$ of the total textiles produced but with the growing awareness for the eco-friendly products, the use of natural dyes will surely bloom in the future (Saxena and Raja, 2014).

According to Heino Lepp, (2011) the term "lichen" is defined as a composite organism that arises from algae or cyanobacteria living among filaments of multiple fungi in a symbiotic relationship. There are about 20,000 lichen species in the world, and India represents $10 \%$ (2305) of the 
known lichens. Many lichens produce secondary compounds, including pigments that had an economic importance as dyes. The Himalayan floraconsist of large number of lichen species that provide excellent source of dyes (Upreti et al., 2010). Except few records of lichen dyes from India so far the dyeing property of lichen are not known. In India, ethnic group of Uttarakhand are known to dye wool from the dyes extracted from lichen species (Kala, 2002).

In the present study an attempt was made to optimize dyeing recipe for silk fabric using lichen, Evernia cirrhatum. Four chemical auxiliaries were selected to study their effect on dyeing ability and colourfastness. These chemical auxiliaries were: Citric acid $\left(\mathrm{C}_{6} \mathrm{H}_{8} \mathrm{O}_{7}\right)$, Sodium sulphate $\left(\mathrm{Na}_{2} \mathrm{SO}_{4}\right)$, Oxalic acid $\left(\mathrm{H}_{2} \mathrm{C}_{2} \mathrm{O}_{4}\right)$ and Tartaric acid $\left(\mathrm{C}_{4} \mathrm{H}_{6} \mathrm{O}_{6}\right)$. After treating dye with the different chemical auxiliaries its colour fastness test was performed along with control sample.

\section{MATERIALS AND METHODS}

Selection of dye: E. cirrhatum (Parmeliaceae, Fig. 1) was selected for the study. The species is widely distributed in tropical and temperate region of India. It is one of the common lichen found in India under the name 'Chharila'. The taxon has ash-grey to grey brown, leafy thallus with dark brown lower surface (Nayaka et al. 2010). It was purchased from Ramnagar market, Nainital, Uttarakhand at the rate of ₹300/kg.

Selection of fabric: Mulberry silk fabric was selected for the study and purchased from Central Silk Board, Dehradun, Uttarakhand at a rate of ₹350/m.

Degumming of silk: Silk was degummed to remove natural impurities and to make it more absorbent. The recipe recommended by Dantyagi (1983) was used. A detergent solution containing $0.5 \mathrm{ml}$ of mild detergent (under local brand name genteel) per $100 \mathrm{ml}$ of water was prepared and then it was heated at $50^{\circ} \mathrm{C}$. Silk fabric was dipped into this solution and stirred gently for about 30 minutes. It was kneaded, squeezed in the soap solution and then rinsed under tap water till free from traces of detergent. After that the fabric was partially dried in shade and ironed when half wet.

Optimization of variables for dyeing: Series of experiments were conducted to determine the various dyeing variables namely medium of dye extraction, concentration of dye material, dye extraction time and dyeing time.

Selection of medium of dye extraction: For optimization of the dye extraction medium, three dye solutions were prepared by using $1.0 \mathrm{~g}$ of dye per $100 \mathrm{ml}$ of water in acidic, alkaline and aqueous media. Acidic solution was prepared by adding 1 $\mathrm{ml}$ of hydrochloric acid in $100 \mathrm{ml}$ of water while the alkaline solution was prepared by adding $1 \mathrm{~g}$ of sodium carbonate in $100 \mathrm{ml}$ of water. Aqueous solutions were prepared by $100 \mathrm{ml}$ of distilled water without using any chemical. All these were boiled at $80^{\circ} \mathrm{C}$ for 60 minutes. After that, the solutions were filtered and pre-soaked silk samples (2 g) were added to each beaker and dyed for 1 hour. Samples were then rinsed in cold water and dried in shade. Each sample was analysed visually and through percent absorption for the depth of the shade obtained and based on it extraction. The media of extraction that yielded better percent absorption of dye and preferred more on visual evaluation was selected as optimised medium of dye extraction.

Optimization of concentration of dye material: Four dye solutions were prepared in separate beaker by adding $2 \mathrm{~g}, 4 \mathrm{~g}, 6 \mathrm{~g}$ and $8 \mathrm{~g}$ of dye material respectively in $100 \mathrm{ml}$ of water and boiled at $80^{\circ} \mathrm{C}$ for 60 minutes. After that, the solutions were filtered and pre-soaked silk samples (2 g) were added to each beaker and dyeing was carried out for 1 hour. Samples were then rinsed in cold water and dried in shade. Each samples were analysed visually and through percent absorption for the depth of the shade obtained. The concentration of dye that produced better percent absorption of dye and preferred more on visual evaluation (Hussain, 2009) was selected as optimised concentration of dye material.

Optimization of time of extraction of dye: Four dye solutions were prepared in separate beaker by extracting the optimum-estimated concentration of the dye material in $100 \mathrm{ml}$ of water which were boiled at $80^{\circ} \mathrm{C}$ for $30,60,90$ and 120 minutes. After that, the solutions were filtered, presoaked silk samples of $2 \mathrm{~g}$ were then added to each beaker and dyeing was carried out for 1 hour. Samples were then rinsed in cold water and dried in shade. Each samples were analysed visually and through percent absorption for the depth of the shade obtained. The dye extraction time that produced better percent absorption of dye and preferred more on visual evaluation (Hussain, 2009) was selected as optimised time of extraction of dye.

Optimization of dyeing time: Four dye solutions were prepared in separate beakers by extracting the optimum-estimated concentration of the dyes material in $100 \mathrm{ml}$ of water at optimum extraction time. $2 \mathrm{~g}$ per-soaked silk samples were added to each beaker and dyed for 30,60, 90 and 120 minutes, respectively. Samples were then rinsed in cold water and dried in shade. Each samples were analysed visually and through percent absorption for the depth of the shade obtained. The dyeing time that produced better percent absorption of dye and preferred more on visual evaluation (Hussain, 2009) was selected as optimised dyeing time.

Optimization of concentration of chemical auxiliaries: Chemical namely citric acid, sodium sul- 
phate, oxalic acid and tartaric acid with four concentrations of each were used as dyeing auxiliary in the study. Four concentrations used for each chemical auxiliary were $1 \%, 2 \%, 3 \%$ and $4 \%$ (o.w.f.). Dyeing solution of each chemical auxiliary concentration were prepared separately using optimized dye concentration and extracted at optimized extraction time. Pre-soaked silk samples of $2 \mathrm{~g}$ were then added to each of the dyeing solution and dyed through simultaneous dyeing method. Samples were then rinsed in cold water and dried in shade. Each samples were analysed visually for the depth of the shade obtained. The concentration of chemical that preferred more on visual evaluation was selected as optimised concentration of chemical auxiliaries.

Colourfastness testing: The dyed samples were subjected to colourfastness testing against light, washing, rubbing and perspiration according to the standard test method namely, colour fastness to light: Test method AATCC-RR 92, 2013; Colour fastness to washing: Test method IS: 3361-2003; Colour fastness to rubbing: Test method AATCCRA 38, 2005 and Colour fastness to perspiration: Test method AATCC-RA 52, 2006 (Pooja et al., 2014).

\section{RESULTS AND DISCUSSION}

The results of the experiments conducted in the study have been discussed as follows:

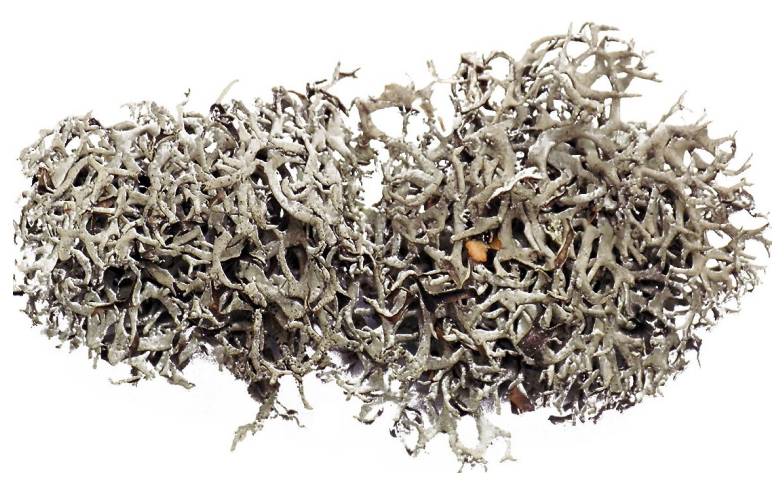

Fig. 1. Evernia cirrhatum

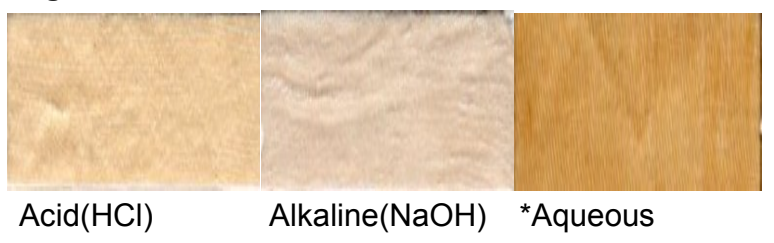

Plate 1. Colour obtained from various media.

Selection of medium of dye extraction: Among the three medium of dye extraction that is acid, alkaline and aqueous medium experimented, aqueous medium gave best result with E. cirrhatum dye. Thus aqueous medium for E. cirrhatum dye was selected for further research. Colours obtain on silk in different medium of extraction are shown in plate 1.

Devi Rajeswari V. et al (2015) reported that mari-

Table 1. Results for optimization of dye concentration.

\begin{tabular}{lllll}
\hline Dye material & Dye concentration $(\mathbf{g})$ & Percent absorption & Percentage rating & Dyed samples \\
\hline $\begin{array}{l}\text { Evernia } \\
\text { cirrhatum }\end{array}$ & 1 & 38.34 & 34 & \\
& ${ }^{*} 2$ & ${ }^{*} 69.44$ & $* 67$ \\
& 3 & 55.55 & 40 \\
& 4 & 59.67 & 48 \\
\end{tabular}

Note- * Selected dye concentration

Table 2. Results for optimization of dye extraction time.

\begin{tabular}{|c|c|c|c|c|}
\hline Dye material & $\begin{array}{l}\text { Dye extraction time } \\
\text { (minutes) } \\
{ }^{*} 60\end{array}$ & $\begin{array}{l}\text { Percent absorption } \\
{ }^{*} 59.47\end{array}$ & $\begin{array}{l}\text { Percentage rating } \\
{ }^{*} 62\end{array}$ & Dyed samples \\
\hline \multirow[t]{3}{*}{$\begin{array}{l}\text { Evernia } \\
\text { cirrhatum }\end{array}$} & 90 & 48.36 & 52 & \\
\hline & 120 & 38.34 & 41 & \\
\hline & 150 & 37.59 & 38 & \\
\hline
\end{tabular}

Note- * Selected dye extraction time 
Table 3. Results for optimization of dyeing time.

\begin{tabular}{lllll}
\hline Dye material & $\begin{array}{l}\text { Dye extraction time } \\
\text { (minutes) }\end{array}$ & Percent absorption & Percentage rating & Dyed samples \\
\hline $\begin{array}{l}\text { Evernia } \\
\text { cirrhatum }\end{array}$ & 30 & 57.64 & 60 \\
& ${ }^{*} 60$ & ${ }^{*} 74.38$ & ${ }^{*} 84.5$ & \\
& 90 & 63.84 & 73.5 & \\
& 120 & 61.46 & 65.5 & \\
\hline
\end{tabular}

Note- * Selected dye extraction time

Table 4. Results for optimization of concentration of chemical auxiliaries.

\begin{tabular}{lllll}
\hline Dye & Chemical auxiliary & Concentration & Percentage Rating & Dyed samples \\
\hline \multirow{2}{*}{ Evernia cirrhatum } & Citric acid & $2 \%$ & 71 & \\
& & & 77 \\
& Sodium sulphate & $2 \%$ & 74 & \\
& Oxalic acid & $3 \%$ & 76 & \\
& Tartaric acid & $4 \%$ & & \\
& & &
\end{tabular}

Table 5. Colour fastness ratings of samples dyed with Evernia cirrhatum using optimum dyeing parameters.

\begin{tabular}{|c|c|c|c|c|c|c|c|c|c|c|c|c|c|}
\hline \multirow[t]{4}{*}{ Dye } & \multirow{4}{*}{$\begin{array}{l}\text { Chemical } \\
\text { Auxiliary }\end{array}$} & \multirow{4}{*}{ Conc } & \multicolumn{11}{|c|}{ Colour fastness grades } \\
\hline & & & \multicolumn{2}{|c|}{ Washing } & \multirow[t]{3}{*}{ Light } & \multicolumn{4}{|c|}{ Rubbing } & \multicolumn{4}{|c|}{ Perspiration } \\
\hline & & & \multirow[t]{2}{*}{ CC } & \multirow[t]{2}{*}{ CS } & & \multicolumn{2}{|c|}{ Dry } & \multicolumn{2}{|l|}{ Wet } & \multicolumn{2}{|c|}{ Acidic } & \multicolumn{2}{|c|}{ Alkali } \\
\hline & & & & & & CC & CS & $\mathrm{CC}$ & CS & $\mathrm{CC}$ & CS & CC & CS \\
\hline \multirow{5}{*}{$\begin{array}{l}\text { Ever- } \\
\text { nia } \\
\text { cir- } \\
\text { rhatu } \\
m\end{array}$} & $\begin{array}{l}\text { Control } \\
\text { sample }\end{array}$ & - & $4 / 5$ & 5 & 6 & 5 & 5 & $4 / 5$ & $4 / 5$ & 5 & 5 & $4 / 5$ & $4 / 5$ \\
\hline & Citric acid & $2 \%$ & 3 & 5 & 4 & $4 / 5$ & $4 / 5$ & $4 / 5$ & 4 & 5 & 5 & $4 / 5$ & $4 / 5$ \\
\hline & $\begin{array}{l}\text { Sodium } \\
\text { sulphate }\end{array}$ & $2 \%$ & 4 & $4 / 5$ & 6 & $4 / 5$ & $4 / 5$ & $4 / 5$ & $4 / 5$ & 5 & 5 & 5 & 5 \\
\hline & $\begin{array}{l}\text { Oxalic } \\
\text { acid }\end{array}$ & $3 \%$ & 2 & $4 / 5$ & 3 & $4 / 5$ & $4 / 5$ & $4 / 5$ & $4 / 5$ & 5 & 5 & 5 & 5 \\
\hline & $\begin{array}{l}\text { Tartaric } \\
\text { acid }\end{array}$ & $4 \%$ & $4 / 5$ & $4 / 5$ & 8 & 5 & 5 & $4 / 5$ & $4 / 5$ & 5 & 5 & 5 & 5 \\
\hline
\end{tabular}

$\mathrm{CC}=$ Colour Change; $\mathrm{CS}=$ Colour Staining

gold flower dye gave best shade on silk fabric in aqueous medium.

Optimization of concentration of dye material: The silk samples were dyed for four different dye concentrations i.e. $1 \mathrm{~g}, 2 \mathrm{~g}, 3 \mathrm{~g}$ and $4 \mathrm{~g}$ for optimizing the concentration of $E$. cirrhatum for dye. The results for different concentration of dye material was reported in Table 1. From the table it was cleared that $2 \mathrm{~g}$ dye concentration per $100 \mathrm{ml}$ of water sample had given the maximum absorption percent $(69.44 \%)$, visual percentage rating $(67 \%)$ and darker shade than the rest of the samples dyed. Hence $2 \%$ dye liquor is considered as the optimum concentration of dye bath (Upreti et al., 2010).
Optimization of dye extraction time: The dye was extracted for the different time period i.e. 60 , 90,120 and 150 minutes. The results of different dye extraction time of dyed material were reported in Table 2. From the table, it was clear that as the timing of dye extraction increases colour shades of the samples became lighter or less bright. The table revealed that out of four dye extraction trial time, maximum absorption percent $(59.47 \%)$ and percentage rating $(62 \%)$ obtained with 60 minutes dye extraction time. Thus, 60 minutes dyeing time was selected as optimum for dye extraction (Shukla et al., 2014).

Optimization of dyeing time: Silk samples were dyed for $30,60,90$ and 120 minutes with 
E. cirrhatum. The dyed samples and result of percent absorption and visual evaluation rating was shown in Table 3. From the table, it was clear that the sample dyed at 60 minutes dyeing time gave the best shade, maximum percentage absorption $(74.38 \%)$ and visual percentage rating $(84.5 \%)$. Hence 60 minute time was selected as optimized dyeing time.

Das et al. (2008) dyed silk fabric with Rheum emodi ( $10 \%$ owf) at $90 \mathrm{C}$ for 60 minutes gave best results.

Optimization of concentration of chemical auxiliaries: The silk samples were dyed using four chemical auxiliaries viz., citric acid, sodium sulphate, oxalic acid and tartaric acid in 1\%, 2\%, 3\% and $4 \%$ concentrations, with simultaneous method and were visually evaluated for the selection of best concentration of each chemical auxiliary. Chemical auxiliaries treated samples and results was reported in Table 4. The optimized concentration of citric acid, sodium sulphate, tartaric acid and oxalic acid for $E$. cirrhatum were $2 \%, 2 \%, 3 \%$ and $4 \%$ respectively.

The dyeing of fabric with natural dyes and varying the $\mathrm{pH}$ of the dyeing bath causes a change in the colour. On lowering the $\mathrm{pH}$ will shift the colour towards orange hues (Dharma Trading Co., 2018)

Testing of dyed samples for colour fastness: Final samples were subjected to colourfastness test for assessing colourfastness of dyed silk samples to light, washing, crocking and perspiration was evaluated.

Colourfastness to light for the dyed samples with tartaric acid showed excellent (8) colour fastness because it change the colour into darker shade when exposed to light, blank sample and sample dyed with sodium sulphate showed very good colour (6) fastness. Washing fastness of the blank samples was considerably good (4/5) as compared to samples treated with chemical auxiliaries. Crocking fastness of dyed samples showed good (5 to 4/5) colour fastness for colour change in both dry and wet conditions. Fastness to perspiration, in case of alkali perspiration blank samples and sample treated with citric acid dyed using $E$. cirrhatum showed, negligible to slightly stain (4/5) for silk samples and negligible stain (5) for rest of the chemical auxiliary treated samples. Fabric dyed with $E$. cirrhatum and treated with chemical auxiliaries showed good colourfastness property (Table 5).

\section{Conclusion}

The study conducted at the laboratory level revealed that natural dye from Evernia cirrhatum can effectively be used for dyeing silk fabric. The aqueous medium of dyeing showed better result on mulberry silk fabric using $E$. cirrhatum dye. Good shades were recorded which varied with the chemical auxiliaries. The recipe optimized for mulberry silk was $2 \mathrm{~g}$ of Evernia cirrhatum dye per 100 $\mathrm{ml}$ of water with 60 minute extraction time and 60 min. dyeing time. In case of chemical auxiliaries, $2 \%$ of citric acid, $2 \%$ of sodium sulphate, $3 \%$ of oxalic acid and $4 \%$ tartaric acid with simultaneous dyeing method was found as best. The dyed silk exhibited good (4) to excellent (5) colour fastness to washing and perspiration, no stain (5) on rubbing and very good (6) for light fastness. The chemical auxiliaries that exhibit best fastness characteristic were sodium sulphate and tartaric acid with fastness grade of good (4) to excellent (5) for washing and perspiration fastness, slight stain to no stain $(4 / 5)$ for rubbing fastness and good (6) to very good (7) for light fastness. Citric acid and oxalic acid washing fastness for change in colour was observed fair (3) to poor (2) however the light fastness recorded between fair (3) to fairly good (4) and good (4) to excellent (5) for washing and perspiration fastness. The optimized dyeing recipes can help the rural women to enhance their skills as well as motivate them to start their business enterprise at home level and cottage level that will generate employment opportunities and can give skill as well as economic empowerment. Further research can also be done on isolation of natural dyes having higher self-life as well as commercial viability.

\section{ACKNOWLEDGEMENTS}

Author is thankful to Dr. Ekta Sharma, Assistant Professor, Ethelind School of Home Science, SHIATS, Allahabad, for her help and support in completion of this work. The study was conducted in the department of Textiles and Apparel designing, Ethelind School of Home Science, SHIATS, Allahabad, is duly acknowledged with thanks.

\section{REFERENCES}

Dantyagi, Susheela (1983). Fundamentals of Textiles and their care, 4th Ed. Orient Longman.

Das, D., Maulik, S. R. and Bhattacharya S. C. (2008). Colouration of wool and silk with Rheum emodi. Indian Journal of Fibre and Textile Research, 33:163170.

Devi Rajeswari V., Jha, C. K., Kumar, R. and Venkat Kumar S. (2015). Extraction of natural dye from marigold flower (Tageteserectal.) and dyeing of fabric and yarns: A focus on colorimetric analysis and fastness properties, Der Pharmacia Lettre, 7 (1):185-195.

Dharma Trading Co. (2018). Natural dyes 101 with Cochineal and Madder Root. Retrieved on March, 12 2018 from https://www.dharmatrading.com/home/ natural-dyes-101-with-cochineal-and-madderroot.html.

Hussain, Arshia (2009). Evaluation of antibacterial activity and UV protection property of cotton fabric dyed with Coreopsis spp. flowers and Cassia fistula bark using optimized dyeing conditions. G.B. Pant University of Agriculture \& Technology, Pantnagar.

Heino Lepp (2011). Australian Lichens. Retrieved De- 
cember, 42014 from https://www.anbg.gov.au/lichen/ what-is-lichen.html.

Kala C. P. (2002). Indigenous knowledge of Bhotia tribal community on wool dyeing and its present status in Garhwal Himalayas, India, Current Science, 83(7): 814-817.

Ministry of Textiles, Government of India (2017). Stitch by stitch the traditional with the modern, Annual report 2016-17.

Maharashtra industrial and economic development association. (2018). Retrieved on February, 152018 from http://www.doingbusinessinmaharashtra. org/ Dyestuff Sector.aspx

Nayaka. S., Upreti, D.K. and Khare, R. (2010). Medicinal lichens of India. In Drugs from Plants (Ed. P.C. Trivedi). Avishkar Publishers, Distributors, Jaipur, India.

Ogugbue C. J. and Sawidis T. (2011). Bioremediation and detoxification of synthetic Wastewater Containing triarylmethane dyes by Aeromonas hydrophila isolated from industrial effluent. Biotechnology $R e-$ search International; DOI 10.4061/2011/967925.

Pooja, Sharma, E. and Fatima, N. (2014). Quality improvement of wool fabric using Protease Enzyme. Environment and Ecology Research, 2(8):301-310.

Przystaś W, Zabłocka-Godlewska E, Grabińska-Sota E. (2012). Biological Removal of Azo and Triphenylmethane Dyes and Toxicity of Process By-Products. Water Air Soil Pollution. 223 (4): 1581-1592.

Saxena, S. and Raja, A. S. M. (2014). Natural Dyes: Sources, Chemistry, Application and Sustainability Issues. Roadmap to Sustainable Textiles and Clothing. Textile Science and Clothing Technology, DOI: 10.1007/978-981-287-065-0_2, pp 77.

Shukla, P., Upreti, D. K., Nayaka, S. and Tiwari, P. (2014). Natural dyes from Himalayan lichens. Indian Journal of Traditional Knowledge. 13(1): 195-201.

Upreti D. K. Joshi S. and Nayak S. (2010). Chemistry of common dye yielding lichens of India, ENVIS Forester Bull, 10(1): 122-133. 